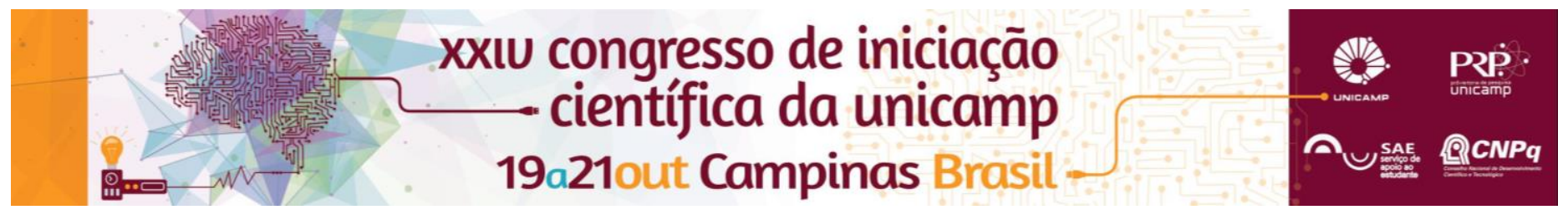

\title{
Avaliação Cefalométrica dos Pacientes com Deformidades Dento-Faciais submetidos à Cirurgia Ortognática
}

\author{
Débora C. Ruiz*, Douglas R. Goulart, Alexander T. Sverzut
}

\begin{abstract}
Resumo
Deformidade é um termo utilizado para designar uma alteração de forma em uma pessoa que se encontra alterada em relação a um padrão estabelecido. As informações contidas na análise cefalométrica são fundamentais para o diagnóstico e o planejamento cirúrgico dos pacientes com deformidades dento-faciais. $O$ objetivo do estudo foi determinar as características cefalométricas dos pacientes com deformidade dento-facial que realizaram tratamento cirúrgico na Faculdade de Odontologia de Piracicaba. Foi realizado um estudo retrospectivo com os prontuários de pacientes com diagnóstico de deformidades dento-faciais atendidos na Área de Cirurgia Buco-Maxilo-Facial da FOPUNICAMP no período de janeiro de 1994 a janeiro de 2015. Foram incluídos os prontuários de paciente com diagnóstico de deformidade dento-facial que foram submetidos à cirurgia ortognática. As telerradiografias de perfil foram digitalizadas por um scanner e transferidas para o Dolphin Imaging Software $\AA^{\circledR}$ (Version 8.0, Chatsworth California), onde foram realizados os traçados cefalométricos utilizando pontos anatômicos e cefalométricos de forma a mensurar as variáveis lineares e angulares. Foram realizadas análises descritiva e comparativa com auxílio do programa de computador SPSS 18.0. Foram incluídos os dados de 86 pacientes com prevalência do gênero feminino $(68,6 \%)$, com idade média de 30,43 anos e leudodermas $(75,6 \%)$, a maior parte dos pacientes foi diagnosticada com deformidade dentofacial classe III e realizou cirurgias combinadas entre maxila, mandíbula e/ou mento $(n=46)$. Os dados encontrados envidenciaram uma relação entre os dados clínicos (gênero e diagnóstico) e a análise cefalométrica realizada.
\end{abstract}

Palavras-chave: Cefalometria; Cirurgia ortognática; Anormalidades maxilofaciais.

\section{Introdução}

Discrepâncias esqueléticas nos maxilares geram problemas funcionais e estéticos que podem influenciar na interação social e qualidade de vida das pessoas. A correção cirúrgica por meio da cirurgia ortognática visa o restabelecimento da oclusão e consequentemente a melhora do perfil facial. A prevalência de pacientes com deformidade dento facial (DDF) que necessitam de correção cirúrgica varia de acordo com a população estudada. Além disso, dentro desta população existem variações quanto ao tipo de deformidade, gênero e cor da pele que influenciam o planejamento cirúrgico e o padrão facial. O objetivo deste trabalho foi estudar as características demográficas e cefalométricas de pacientes com deformidade dento facial submetidos a cirurgia ortognática pela Área de Cirurgia Bucomaxilofacial da FOP-UNICAMP.

\section{Resultados e Discussão}

Este estudo incluiu 86 prontuários de pacientes em que foram coletados dados demográficos e do tratamento empregado e a partir da telerradiografia de perfil préoperatória foi realizada a avaliação cefalométrica utilizando o programa de computador Dolphin Imaging ${ }^{\circledR}$. A amostra foi composta por 59 mulheres $(68,6 \%)$ e 27 homens $(31,4 \%)$. A maior parte dos pacientes declarou apresentar pele branca $(75,6 \%)$, seguida por pardos $(22,1 \%)$ e negros $(2,3 \%)$. A maioria foi diagnosticada com DDF Classe III $(53,5 \%)$, seguido pela Classe II $(46,5 \%)$ de Angle. Quanto ao tratamento cirúrgico, quarenta pacientes realizaram cirurgia em apenas em um dos maxilares $(n=40)$, sendo destes em 20 pacientes a cirurgia foi na maxila (Osteotomia tipo Le Fort I) e 20 na mandíbula (Osteotomia Sagital do Ramo Mandibular). A Tabela 1 apresenta a comparação das variáveis cefalométricas para os pacientes segundo o diagnóstico.

\begin{tabular}{|c|c|c|c|c|}
\hline & Diagnóstico & Média & Desvio padrâo & $p$ \\
\hline \multirow{2}{*}{ ANB } & Classe II & 7,31 & 3,15 & $<0,01$ \\
\hline & Classe III & $-1,30$ & 3,36 & \\
\hline \multirow{2}{*}{ SNA } & Classe II & 86,13 & 5,71 & 0,769 \\
\hline & Classe III & 86,48 & 5,47 & \\
\hline \multirow{2}{*}{ SNB } & Classe II & 78,80 & 4,43 & $<0,01$ \\
\hline & Classe III & 87,85 & 5,61 & \\
\hline \multirow{2}{*}{ plano oclusal-sn } & Classe II & 15,70 & 4,55 & $<0,01$ \\
\hline & Classe III & 11,64 & 5,94 & \\
\hline \multirow{2}{*}{ FMA } & Classe II & 28,83 & 9,33 & $<0,01$ \\
\hline & Classe III & 23,82 & 7,32 & \\
\hline \multirow{2}{*}{ n.perp-A } & Classe II & 2,63 & 5,27 & 0,795 \\
\hline & Classe III & 2,35 & 4,01 & \\
\hline \multirow{2}{*}{$\mathrm{CO}-\mathrm{A}$} & Classe II & 80,36 & 13,26 & 0,222 \\
\hline & Classe III & 83,03 & 5,77 & \\
\hline \multirow{2}{*}{ Co-Gn } & Classe II & 105,39 & 17,19 & $\Leftrightarrow 0,01$ \\
\hline & Classe III & 121,67 & 8,21 & \\
\hline \multirow{2}{*}{ Pg.-nperp } & Classe II & $-6,7317$ & 10,62 & $\Leftrightarrow 0,01$ \\
\hline & Classe III & 10,06 & 9,47 & \\
\hline
\end{tabular}

\section{Conclusões}

As características clínicas das deformidades dento faciais são acompanhadas por alterações na face que podem ser observadas por meio da cefalometria. Foi observada diferença estatisticamente significativa entre os pacientes diagnosticados como classe II e III para as variáveis: ANB, SNB, Plano oclusal, FMA, n.perp-a, Cogn e Pg-n.perp. As características observadas podem auxiliar no diagnóstico e a programas voltados para 0 tratamento de deformidades faciais no Brasil.

1. Janson G, Quaglio CL, Pinzan A, Franco EJ, Freitas MR De. Craniofacial characteristics of Caucasian and Afro-Caucasian Brazilian subjects with normal occlusion. 2011;19(2):118-24

2. Boeck EM, Eiras K, Coletta D, Jorge R, Neto B. Occurrence of Skeletal Malocclusions in Brazilian Patients with Dentofacial Deformities. 2011;22:340-5. 